\title{
TA'ZIR DALAM LEMBAGA KEUANGAN ISLAM
}

\author{
Ruslan Husein Marasabessy \\ STAI Asy-Syukriyyah Tangerang \\ rully.ief@gmail.com
}

\begin{abstract}
Fines and sanctions are known in Jurisprudence (Islamic criminal law) and not in the scope of civil law. Because these ta'zir sanctions are ijtihadi. this is different from sanctions that are tauqifi,where the provisions are contained in the quran and hadith, then it takes an effort initiative (ijtihad) to determine it. Ta'zir in Islamic criminal law is applied physically, then sanctions appear in the form of fines.The scholar of Moslem differed on their views on whether this ta'zir maliyyah (fines) could be applied in the context of financial institutions. Some Moslem Scholars who allow fines material ta'zir (al gharamah al uqubah al maliyyah) is Imam Abu Yusuf (the Schollars of Hanafiyyah). otherwise, some scholars banned this sanction, the reason is that Islam forbidden to take the rights of other parties unfairly. Indonesian national sharia council (DSN MUI), issuing a decision of this matter on Fatwa DSN MUI no 17 2009, about the possibility of fines in Islamic financial institutions, with the foundation of the proposition that is used as a reference. to provide guidance to the public about the existence of fines or ta'zir in Islamic financial institutions. public misunderstanding of this matter is directly related to the reputation and perception of Islamic financial institutions.
\end{abstract}

Keywords: fines, ta'zir, Fiqh Muamalah, Islamic financial institutions

\section{PENDAHULUAN}

Kualitas pelayanan adalah aspek yang sangat penting dalam dunia perbankan secara umum. Bank yang memberikan pelayanan buruk akan berimplikasi negatif, hal ini berdasarkan hasil dari beberapa peneliti yang telah meneliti hubungan yang erat antara kualitas pelayanan dan sasaran marketing, tingkat keuntungan, kepuasan nasabah dan loyalitas yang menyatakan bahwa kualitas pelayanan berhubungan erat dengan tingkat kepercayaan atau sikap nasabah sehingga dapat menghasilkan tingkat pelayanan yang baik.

Salah satu upaya untuk meningkatkan kualitas pelayanan bank syariah yaitu dengan menjaga kesesuaian produk dengan prinsip syariah yang menjadi pembeda bank syariah dengan bank konvensional. Keberhasilan sebuah Bank dalam mengelola reputasi dan pelayanan dapat dilihat dari tingkat kepuasan nasabah. Oleh karena itu bank harus memperhatikan tuntutantuntutan nasabah yang selalu berkembang tiap waktunya.

Choudhury juga mengindikasikan bahwa tingkat pelayanan yang baik dalam perusahan akan menghasilkan stigma yang positif dari nasabah terhadap perusahan, termasuk di antaranya merekomendasikan hal yang positif kepada orang lain tentang perusahan, mengakomodasi nasabah lain untuk berinteraksi dengan perusahan, melakukan bisnis dengan perusahan, dan 
mempertimbangkan perusahan sebagai pilihan pertama dalam kegiatan bisnis. Hubungan antara kepuasan pelayanan dan loyalitas nasabah secara teori dan empiris telah terbukti dalam literature dalam service industry termasuk di dalamnya bank dan perkembangannya.

Salah satu aspek yang berpengaruh terhadap reputasi Perbankan Syariah adalah produk dalam sistem perbankan Syariah.Karena sangat mempengaruhi reputasi dari Bank Syariah itu sendiri di tengah masyarakat. Salah satu aspek dalam operasional perbankan Syariah yang kemudian banyak di kritisi dan menjadi perdebatan di tengah masyarakat adalah adanya dengan atau ta'dzir dalam pembiayaan dan akad dalam perbankan maupun Lembaga keuangan Syariah.

Lembaga keuangan syariah yang mewajibkan Nasabah untuk membayar sejumlah uang jika melanggar kesepakatan yang sudah ditetapkan di dalam aka. Ini dilakukan agar nasabah patuh dan disiplin terhadap kewajibannya dan sebagai ta'zir bagi para pelanggarnya. Sehingga kemudian muncul pembahasan apakah boleh ta'zir dengan membayar uang dan Bagaimana hukumnya?

DSN MUI telah banyak mengeluarkan fatwa untuk di jadikan panduan Lembaga keuangan Syariah dalam operasional dan pengembangan produknya di antaranya adalah Fatwa DSN MUI nomor 17 Tahun 2000 tentang Sanksi atas Nasabah Mampu yang menunda nunda pembayaran.sebagian masyarakat kemudian menganggap bahwa denda ini adalah sebuah praktik yang menyerupai riba dalam praktik Lembaga keuangan Syariah.untuk itulah kemudian di butuhkan sebuah kajian untuk membahas lebih jauh tentang ta'dzir ini sendiri dalam praktik Lembaga keuangan syariah.

\section{METODE PENELITIAN}

Tulisan ini merupakan hasil penelitian kepustakaan (library research). Jenis penelitian kepustakaan merupakan penelitian yang mengandalkan data-data yang hampir sepenuhnya dari kepustakaan atau literatur, baik itu dalam bentuk fisik maupun digital. Penelitian ini lebih popular dikenal dengan penelitian kualitatif deskriptif kepustakaan atau penelitian bibliografis, dan juga dapat diistilahkan Non Reaktif yang sepenuhnya menggunakan data-data yang bersifat teoritis dan dokumentasi yang ada di perpustakaan.

Peneliti memperoleh data dari hasil studi kepustakaan dari berbagai literatur buku, jurnal, karya ilmiah, dan juga dokumen-dokumen lain yang mengkaji terkait Ta'zir Dalam Lembaga Keuangan Islam. 


\section{PEMBAHASAN}

\section{Ta'dzir}

Hukuman ta'zir adalah hukuman yang belum ditetapkan oleh syara', melainkan diserahkan kepada hakim, baik penentuannya maupun pelaksanaannya. Syara' tidak menyebutkan secara spesifik hukuman untuk tiap-tiap jarimah ta'zir, tetapi hanya menyebutkan sekumpulan hukuman, dari yang paling ringan hingga hukuman yang berat. Dalam hal ini hakim diberikan keleluasaan untuk memilih hukuman yang sesuai dengan hukuman $t a$ 'zir terhadap pelaku jarimah. Jadi hukuman $t a{ }^{\prime}$ zir tidak memiliki batasan tertentu ${ }^{1}$

\section{Jenis jenis hukum ta'dzir}

Dari sisi dalil dalam Al-Qur'an atau Al-Hadits, Maka Hukuman dibagi menjadi dua ${ }^{2}$, yaitu:

1. Hukuman yang ada nashnya, yaitu hudud, qishash, diyat, dan kafarah. Misalnya, hukuman bagi pezina, pencuri, perampok, pemberontak pembunuh, dan yang menzihar istrinya (menyerupakan istrinya dengan ibunya).

2. Hukuman yang tidak ada nashnya, hukuman ini disebut ta'zir, percobaan melakukan jarimah, jarimah hudud, Qisas atau diyat.

Ditinjau dari keterkaitan antara hukuman yang satu dengan hukuman lainya,maka terbagi menjadi empat :

1. Hukuman pokok (Al-'Uqubat Al-Asliyah), yaitu hukuman utama bagi suatu kejahatan, hukuman mati bagi pembunuhan yang di lakukan dengan sengaja, hukuman diyat bagi pelaku pembunuhan tidak sengaja, dera (jilid) seratus kali bagi pezina ghairah muhsan.

2. Hukuman pengganti (Al- 'Uqubat Al-Badliyah), hukuman yang menggantikan hukuman pokok (hukuman asli) karena suatu alasan tidak bisa dilaksanakan, sepeti hukuman ta'zir dijatuhkan bagi pelaku jarimah had yang didakwakan hukuman diyat diberikan bagi pembunuhan sengaja yang dimaafkan keluarga korban. Dalam hal ini hukuman ta'zir merupakan hukuman pengganti dari hukuman asal.

3. Hukuman tambahan (Al-'Uqubat Al-Taba'iyah), yaitu hukuman yang dikenakan yang berkaitan dengan hukuman pokok. Seorang pembunuh pewaris, tidak berhak mendapat warisan dari harta si terbunuh.

\footnotetext{
${ }^{1}$ Ahmad Hanafi. 1990. Asas-Asas Hukum Pidana Islam. (Jakarta: PT. Bulan Bintang) h. 75

${ }^{2}$ Rahmat Hakim. Hukum Pidana Islam. () h. 67
} 
4. Hukuman pelengkap (Al-'Uqubat Al-Takhmiliyyah), yaitu hukuman untuk melengkapi hukuman pokok yang telah dijatuhkan, namun harus melalui keputusan hakim.

Para Fuqoha menentukan batas maksimal sanksi hukuman ta'zir yaitu:

1. Hukuman ta'zir itu diterapkan dengan pertimbangan kemaslahatan dan dengan memperhatikan kondisi fisik terhukum.

2. Hukuman yang dijatuhkan tidak boleh melebihi hukuman had.

3. Hukuman ta'zir b diberikan dengan batas maksimal tidak boleh melebihi 10 kali cambukan

\section{Ta'zir dalam fikih Muamalah}

Ta 'zir pada umumnya di kenal dalam fikih Jinayah (Hukum Pidana Islam) Dalam Kitab Al Tasyri' al Jina'i al Islami : Muqaran Bil Qanun al wadhi,Abdul Qadir Audah ${ }^{3}$ menjelaskan bahwa hukuman atau ta'zir merupakan sanksi yang sifatnya ijtihadi, bukan sanksi yang sifatnya tauqifi yang ketentuannya terdapat di dalam al Qur'an dan Hadits Nabi Muhammad Saw. Sebagaimana sanksi Qishash dan diyat, oleh sebab itu ta'zir merupakan sanksi yang sifatnya ijtihad.

\section{Ragam Sanksi ${ }^{4}$}

\begin{tabular}{|l|l|}
\hline Konsep & Deskripsi \\
\hline Al-Jild & Sanksi Cambuk \\
\hline Al-habs & Sanksi Kurungan \\
\hline Al-Taghrib & Sanksi Pembuangan/Kurungan \\
\hline AL-Shalb & Sanksi penyaliban \\
\hline Al-Wa'zh & Sanksi Teguran \\
\hline Al-Hajr & Sanksi Pemutusan hubungan \\
\hline Al-taubikh & Sanksi Celaan (di masukkan daftar orang tercela) \\
\hline Al-Tahdid & Sanksi (Hukum Percobaan) \\
\hline Al-Tasyhir & Sanksi Publikasi \\
\hline Al-Kashshah & Sanksi pengurangan hak (di cabut hak pilih) \\
\hline Al-Gharamah & Sanksi Harta (denda dan ganti rugi ta'widh) \\
\hline
\end{tabular}

\footnotetext{
${ }^{3}$ Kitab Al Tasyri' al Jina'I al Islami: Muqaran Bil Qanun al wadhi,Abdul Qadir Audah h. 34

${ }^{4}$ Muhammad Al Zuhailli,al nazhjariyyat al Fiqhiyyah. 1993 (Damaskus : Dar el Qalam) h. 64-66
} 
Sanksi Gharamah merupakan ta'zir yang dapat berupa Gharamah al uqubah al maliyyah.Sanksi ini menarik karena biasanya sanksi di bebankan pada fisik,selain itu Wahbah Zuhaili memperkaya khazanah sanksi ta'zir yaitu mengembangkan ke area psikologis atau di permalukan. Sanksi berupa denda (Al Gharamah al uqubah al maliyyah) termasuk wilayah ijtihadi.oleh karena itu ada ulama yang membolehkan dan ada yang tidak membolehkan.

Lembaga keuangan Syariah di Indonesia mewajibkan nasabah untuk membayar sejumlah uang/denda jika tidak memenuhi kewajibannya di dalam akad yang sudah di sepakati dengan Lembaga keuangan Syariah. Mayoritas ulama Syafiiyah mengatakan bahwa ta'zir dengan membayar uang atau mengambil harta benda tidak diperbolehkan. Mereka berpandangan bahwa ta'zir atau denda tidak diberlakukan dengan mengambil uang atau harta, melainkan diberlakukan sebatas pada hukuman fisik. Hal ini karena tujuan ta'zir adalah mendidik, bukan merusak atau mengambil uang dan harta benda. Hal ini sebagaimana telah dijelaskan dalam kitab Tanwirul Qulub berikut;

$$
\text { ولا يجوز التعزير بحلق اللحية ولا بأخذ المال }
$$

“Tidak boleh menta'zir (menghukum) dengan mencukur jenggot atau dengan mengambil harta."

Imam al-Baihaqi dalam kitab Sunan al-Kubra juga menyebutkan pendapat Imam Syafii yang tidak membolehkan ta'zir dengan membayar uang atau mengambil harta. Beliau berkata:

$$
\text { قال الثافعي: لا تضعف الغر امة على أحد في شيء إنما العقوبة في الأبدان لا في الأموال }
$$

"Imam Syafii berkata, 'Denda tidak diperlakukan dengan mengambil sesuatu, hukuman diperlakukan sebatas pada raga, bukan pada harta."

Sementara Ulama Hanafiyah membolehkan ta'zir dengan membayar uang atau mengambil harta, dengan catatan dikembalikan lagi pada pemiliknya setelah dia bertaubat. Dalam kitab alFiqh 'ala Mazahibil 'Arba'ah disebutkan sebagai berikut;

$$
\text { واجاز بعض الحنفية التعزير بالمال على انه اذا تاب يرد له }
$$

“Sebagian ulama Hanafiyah membolehkan ta'zir dengan cara mengambil harta namun wajib dikembalikan apabila pelakunya telah bertobat."

Sementara itu, sebagian tabi'in dan Syaikh Abdul Qohir al-Maghribi membolehkan ta'zir dengan mengambil harta dan tidak perlu dikembalikan pada pemiliknya meskipun dia bertaubat. Akan tetapi harta tersebut digunakan untuk kepentingan umum atau dimasukkan ke kas lembaga.

Hal ini sebagaimana telah dijelaskan dalam kitab Yaqutun Nafis berikut: 


$$
\begin{aligned}
& \text { و هل يجوز التعزير بالغرامة المالية ؟ المذاهب الأربعة لا تجيز التعزير بالتغريم لكن بعض التابعين والثيخ عبد القاهر }
\end{aligned}
$$

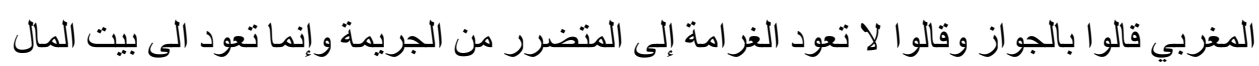

“Apakah boleh ta'zir dengan hukuman harta? Empat mazhab tidak membolehkan ta'zir dengan mengambil harta, akan tetapi sebagian tabi'in dan Syaikh Abdul Qohir al-Maghribi mengatakan boleh. Mereka mengatakan, harta tersebut tidak perlu dikembalikan pada orang yang telah melanggar aturan, namun dikembalikan pada baitul mal (kas umum)."

Berkaitan dengan transaksi keuangan, dasar hukum untuk menentukan sanksi berupa ta'zir terdapat dua perbuatan yang harus di hindari, kezaliman (Zhulm) dan lalai/melampaui batas (al Ta'addi). Dalilnya adalah Hadits Nabi Muhammad Saw dalam riwayat jamaah (Bukhari dari Abu Hurairah, Tirmizi dari Abu Hurairah dan Ibnu Umar, Nasa'i dari Abu Hurairah, Abu Daud dari Abu Hurairah, Ibn Majah dari Abu Hurairah dan Ibn Umar, Ahmad dari Abu Hurairah dan Ibn Umar, Malik dari Abu Hurairah,dan Darami dari Abu Hurairah),

Rasulullah saw bersabda: "Sikap menunda-nunda pembayaran utang oleh pihak yang mampu merupakan kezaliman,dan apanila utang salah seorang di antara kamu di alihkan kepada pihak yang mampu maka hendaknya ia menerimanya"

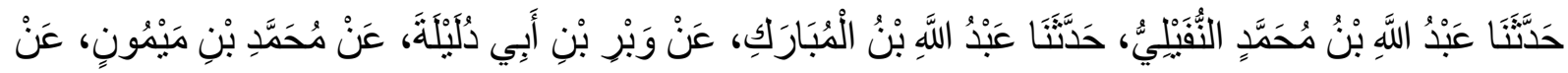

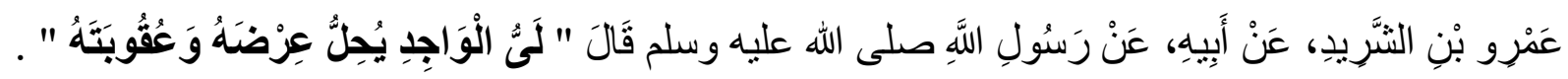

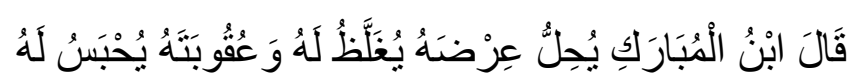

"Menunda-nunda (pembayaran) yang dilakukan oleh orang yang berada (orang yang mampu), itu menghalalkan harga diri dan pemberian sanksi (materi) kepadanya."

Hadits berikutnya:

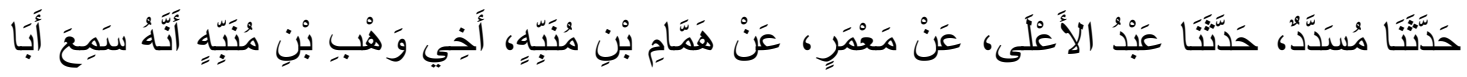

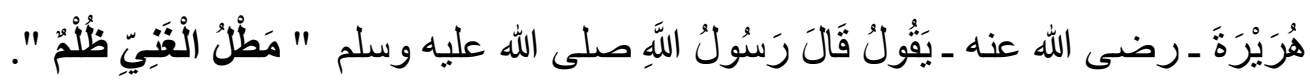

"Penundaan (pembayaran) yang dilakukan oleh orang yang mampu adalah kezhaliman."

Muhammad al Zuhailli mengatakan bahwa Ulama Abu Yusuf (pengikut Abu Hanifah) membolehkan adanya sanksi berupa ta'zir kebendaan (al gharamah al uqubah al maliyyah) 
misalnya denda. Jumhur Ulama melarangnya karena khawatir akan terjatuh kepada riba atau pengambilan harta milik pihak lain secara zalim karena bukan haknya. ${ }^{5}$

Ahmad Mustafa Afifi Dalam Kitab Radd al Mukhatar ala al durr al mukhtar Ibn Abidin,kita kasyaf al qina an matn al iqna,dan kitab Al Hisbah fil Islam karya Ibn Taimiyah di jelaskan bahwa Jumhur ulama telah sepakat (Ijma) tentang tidak bolehnya mengambil harta pihak lain sebagai ta'zir karena termasuk tindakan aniaya dan zhulm tanpa syarat yang benar.

Hadits yang di jadikan dasar adalah hadits riwayat Ibnu Majah dan Imam al Baihaqi dari Fatimah binti Qaisyi yang menyatakan bahwa Rasulullah saw bersabda tidak berhak mengambil harta seseorang secara paksa selain pengambilan zakat ${ }^{6}$

Pendapat Abu Yusuf yang membolehkan sanksi ta'zir berupa denda juga mendapat dukungan dari ulama lainnya.di antara dalil yang di gunakan adalah hadits Nabi Saw,riwayat Nasa'I dan Syuraid bin Suwaidi,Abu Daud Dari Syuraid,dan Ahmad dari Syuraid,Rasulullah saw bersabda:

Menunda nunda (pembayaran utang) yang dilakukan oleh orang yang mampu membuat yang bersangkutan halal harga dirinya dan halal di sanksi

Dalam kitab fatawa mausu'ah al muamalat maliyyah,Syaikh ALI Jum'ah dkk dijelaskan pendapat Ibnu Taimiyah yang menyatakan bahwa siapa yang memiliki uang,tetapi tidak membayarnya padahal yang bersangkutan mampu untuk membayarnya maka yang bersangkutan boleh di kenakan sanksi dengan (Ta'dzir) karena yang bersangkutan mumathil (menunda nunda pembayaran utang) dan termasuk zalim,sanksi dan denda di bolehkan juga berdasarkan kebiasaan yang berlaku.

Dalam kitab fiqh muamalah al maliyyah Rafiq Yunus al Mishri menjelaskan argument di bolehkan sanksi berupa denda, yaitu analogi pada hukum zakat yaitu boleh di berikan sanksi pihak yang menolak membayar zakat dengan mengambil setengah hartanya.

Muhammad Biltazi dalam kitab al Jinayat wal Uqubat fi al Islam wal Huquq al insan,menyatakan bahwa pendapat yang melarang sanksi kebendaan (al gharamah al-uqubah al maliyyah) sudah tidak relevan dari segi argumentasinya karena ada dua alasan :

\footnotetext{
${ }^{5}$ Muhammad Al Zuhailli. 1993 Al Nazhariyyat al Fighiyyah. (Damaskus Dar el Qalam) h. 66

${ }^{6}$ Ahmad Mushtafa Afifi, 2003. al Ihtikar wa mawqif al syar'iyyah AL Islamiyyah minhu fi Ithar al alaqat al Iqtishadiyyat al Mu'ashirah. (kairo maktabah Wahbah) h. 204-206
} 
1. Banyaknya peraturan perundang-undangan yang membolehkan gharamah

2. Terdapat beberapa institusi yang membolehkan mengambil atau menguasai harta seseorang selain zakat.

\section{Fatwa DSN no 17 tahun 2000 tentang ta'dzir}

Fatwa Dewan Syari'ah Nasional No: 17/Dsn-Mui/Ix/2000 Tentang Sanksi Atas Nasabah Mampu Yang Menunda-Nunda Pembayaran. Berikut poin-poin dari sanksi yang ditetapkan:

1. Sanksi yang disebut dalam fatwa ini adalah sanksi yang dikenakan LKS kepada nasabah yang mampu membayar, tetapi menunda-nunda pembayaran dengan disengaja.

2. Nasabah yang tidak/belum mampu membayar disebabkan force majeur tidak boleh dikenakan sanksi.

3. Nasabah mampu yang menunda-nunda pembayaran dan/atau tidak mempunyai kemauan dan itikad baik untuk membayar hutangnya boleh dikenakan sanksi.

4. Sanksi didasarkan pada prinsip ta'zir, yaitu bertujuan agar nasabah lebih disiplin dalam melaksanakan kewajibannya.

5. Sanksi dapat berupa denda sejumlah uang yang besarnya ditentukan atas dasar kesepakatan dan dibuat saat akad ditandatangani.

6. Dana yang berasal dari denda diperuntukkan sebagai dana sosial. Kedua : Jika salah satu pihak tidak menunaikan kewajibannya atau jika terjadi perselisihan di antara kedua belah pihak, maka penyelesaiannya dilakukan melalui Badan Arbitrasi Syari'ah setelah tidak tercapai kesepakatan melalui musyawarah. Ketiga : Fatwa ini berlaku sejak tanggal ditetapkan dengan ketentuan jika di kemudian hari ternyata terdapat kekeliruan, akan diubah dan disempurnakan sebagaimana mestinya.

\section{Pertimbangan Sosiologis Fatwa DSN-MUI nomor 17 tahun 2000 tentang Ta'zir ${ }^{7}$}

- Masyarakat banyak memerlukan pembiayaan dari Lembaga Keuangan Syariah berdasarkan prinsip jual beli maupun akad yang lain yang pembayarannya secara angsuran.

- Nasabah mampu terkadang menunda nunda kewajiban pembayaran baik dalam akad jual beli maupun akad yang lain,pada waktu yang di tentukan berdasarkan kesepakatan kedua belah pihak

\footnotetext{
${ }^{7}$ Prof Dr Jaih Mubarok. 2017. Fikih Muamalah Maliyyah Prinsip prinsip Perjanjian (Simbiosa Media) h. 98
} 
- Masyarakat dalam hal ini LKS meminta fatwa kepada DSN tentang tindakan atau sanksi apa yang dapat di lakukan terhadap nasabaj mampu yang menunda nunda pembayaran menurut Syariah Islam

- Oleh karena itu DSN perlu menetapkan fatwa tentang sanksi atas nababah mampu yang menunda nunda pembayaran menurut prinsip Syariah Islam,untuk di jadikan pedoman oleh LKS

\section{Substansi dan Ketentuan dalam Fatwa No 17 tahun 2000 tentang sanksi atas nasabah mampu yang menunda pembayaran}

- Sanksi yang di sebutkan dalam Fatwa ini adalah Sanksi yang di kenakan LKS terhadap Nasabah yang mampu membayar,tapi menunda dengan sengaja.

- Nasabah yang tidak/belum mampu membayar di sebabkan force majeur tidak boleh di kenakan sanksi.

- Nasabah mampu yang menunda nunda pembayaran dan atau tidak mempunyai kemauan dan Itikad baik untuk membayar utangnya boleh di kenakan sanksi.

- Sanksi di dasarkan pada prinsip ta'zir yang bertujuan agar nasabah lebih disiplin dalam melaksanakan kewajibannya.

- Sanksi dapat berupa denda sejumlah uang yang besarnya ditentukan atas dasar kesepakatan dan di buat pada saat akad di tandatangani.

- Dana yang berasal dari denga di peruntukkan dana sosial.

- Dalam fatwa tersebut memang tidak terdapat dua dalil hadits Nabi saw tentang bolehnya pihak yang berutang di kenakan sanksi apabila tidak membayar hutang karena lalai bukan karena ketidakmampuannya.

\section{KESIMPULAN}

Secara umum ta'dzir biasanya dikenal dalam fikih jinayah, Sanksi berupa denda ( $A l$ Gharamah al uqubah al maliyyah) termasuk wilayah ijtihadi.oleh karena itu ada ulama yang membolehkan dan ada yang tidak membolehkan sebagaimana pemaparan di atas. Fatwa mui dalam hal ini fatwa DSN no 17 tahun 2000 memiliki pandangan yang berbeda sebagaimana Ulama klasik juga memiliki pandangan yang berbeda,DSN MUI melihat dari sisi keamanahan dan kedisiplinan,serta yang harus di garis bawahi bahwa denda atau ta'zir ini di kenakan kepada nasabah yang mampu membayar tapi dengan sengaja menunda,akan tetapi kepada nasabah yang tidak memiliki kemampuan membayar tidak boleh di kenakan ta'zir 
Denda/ta'zir tidak boleh di akui sebagai profit atau keuntungan akan tetapi di masukkan sebagai dana tabarru yang peruntukkannya akan di berikan kepada fakir Miskin. Bank Syariah harus mengklasifikasikan Nasabah yang masuk dalam kategori tidak mampu sehingga kemudian fatwa DSN MUI no 17 tahun 2000 dapat di aplikasikan dengan baik

\section{DAFTAR PUSTAKA}

Al Zuhailli, Muhammad. 1993. Al Nazhjariyyat al Fiqhiyyah Damaskus: Dar el Qalam

Audah, Abdul Qadir. Kitab Al Tasyri' al Jina'I al Islami: Muqaran Bil Qanun al wadhi

Dealey, C. 1999. The Care of Wounds: A Guide for Nurses. Oxford: Blackwell Sciences. Dari NetLibrary, (Online). (http://www.netlibrary.com), diakses 24 Agustus 2007.

Hanafi, Ahmad. 1990. Asas-Asas Hukum Pidana Islam. Jakarta: PT. Bulan Bintang.

Margono. 2007. Manajemen Jurnal ilmiah. Dalam M.G. Waseso \& A. Saukah (Eds.), Menerbitkan Jurnal Ilmiah (hlm.41-59). Malang: Penerbit Universitas Negeri Malang.

Marzuki, M.S. 2009. Permainan Simulasi di Indonesia. Malang: Fakultas Ilmu Pendidikan Universitas Negeri Malang.

Mubarok, Jaih. 2017. Fikih Muamalah Maliyyah Prinsip prinsip Perjanjian. Simbiosa Media.

Mushtafa, Ahmad Afifi. 2003. Al Ihtikar wa mawqif al syar'iyyah AL Islamiyyah minhu fi Ithar al alaqat al Iqtishadiyyat al Mu'ashirah. Kairo maktabah Wahbah.

Wiyono, M. 2009. Profesionalisme Dosen dalam Program Penjaminan Mutu. Jurnal Ilmu Pendidikan, 16 (1): 51-58.

Yamin, H.M. 2007. Profesionalisasi Guru \& Implementasi KTSP. Jakarta: GaungPersada Press. 